\title{
Vénus Khoury-Ghata, Ortiche
}

\section{Ilaria Vitali}

\section{(2) OpenEdition}

\section{Journals}

\section{Edizione digitale}

URL: http://journals.openedition.org/studifrancesi/9066

DOI: 10.4000/studifrancesi.9066

ISSN: 2421-5856

\section{Editore}

Rosenberg \& Sellier

\section{Edizione cartacea}

Data di pubblicazione: 1 octobre 2008

Paginazione: 501

ISSN: 0039-2944

\section{Notizia bibliografica digitale}

Ilaria Vitali, «Vénus Khoury-Ghata, Ortiche», Studi Francesi [Online], 155 (LII | II) | 2008, online dal 30

novembre 2015, consultato il 11 janvier 2021. URL: http://journals.openedition.org/studifrancesi/9066 ; DOI: https://doi.org/10.4000/studifrancesi.9066

Questo documento è stato generato automaticamente il 11 janvier 2021.

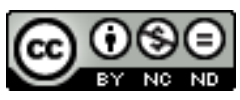

Studi Francesi è distribuita con Licenza Creative Commons Attribuzione - Non commerciale - Non opere derivate 4.0 Internazionale. 


\title{
Vénus Khoury-Ghata, Ortiche
}

\author{
Ilaria Vitali
}

\section{NOTIZIA}

VÉNUS KHOURY-GHATA, Ortiche, prefazione, traduzione e cura di Fabio scotTo, testo francese a fronte, Rovigo, Il Ponte del Sale, 2007, pp. 51.

1 Pianta urticante tra le più invasive, l'ortica è lo spunto poetico sfruttato da Vénus Khoury-Ghata per stilare un singolare erbario emotivo in forma poetica. Tracciando il parallelo tra scrittura e orticoltura, tra parola e seme, l'autrice libanese, tra le più note del panorama francofono, racconta in Ortiche il vissuto dell'infanzia in Libano, «terra solare e martoriata» (p.9). L'austerità del passato emerge attraverso il ricordo petroso di una natura infida, di una casa angusta nel nord del paese, accerchiata dal regno sovrano delle ortiche. Per la sua natura infestante, l'ortica diviene così simbolo e pretesto: simbolo dell'aridità del paese natale, della guerra incombente, della minaccia di invasione e morte; pretesto per dire il dramma familiare, quello di un passato doloroso e - come l'ortica - difficile da estirpare.

2 Attraverso una costruzione metafinzionale che rende complice il lettore, l'autrice incontra sulla pagina scritta i suoi personaggi, figure di carta che col procedere della narrazione poetica svelano a poco a poco la loro precisa identità. Si tratta della madre, «vecchia china fino a terra» (p.19), dello zio, carpentiere e becchino, e del fratello poeta, figure ancestrali che rivestono un ruolo di primo piano nella produzione dell'autrice libanese, e in particolare nel romanzo Une maison aux bords des larmes, che racconta le vicissitudini familiari e il dramma del fratello, fatto internare dal padre in un manicomio. Qui appena abbozzata, la figura del padre-padrone la cui ira «ribaltava la casa» (p.35), rimane pur sempre ossessione dell'autrice, che sembra non poterne sradicare il ricordo.

3 Erba infestante, l'ortica ha però anche proprietà terapeutiche, come sembra averne la scrittura per Vénus Khoury-Ghata, che ha più volte dichiarato di scrivere con la penna del fratello, privato troppo presto della vis scribendi: «Ho preso in mano la penna al suo 
posto quando non poté più scrivere. Ho scritto sul suo quaderno d'appunti. Avevo l'impressione che mi dettasse le mie poesie» (p. 12).

4 La bella traduzione di Fabio Scotto, traduttore e soprattutto poeta, restituisce appieno il valore del testo originale, la sua musicalità, la ricchezza semantica e stilistica dettata dal prezioso incedere di metafore filanti. Giocando su immagini evocative, il campo semantico della botanica riesce a rendere viva l'operazione della scrittura e il suo rovescio intimo. «Il rastrello in una mano | la matita nell'altra» (p. 49), Vénus KhouryGhata ci conduce nel suo mondo reale e finzionale al tempo stesso, dove riaffiorano $i$ ricordi e i personaggi nascono dal contatto tra la penna e la carta. Bellissime alcune immagini che intessono sans couture visible il legame tra la scrittura e il vivido mondo vegetale, delineando in modo sempre più preciso il mondo poetico dell'autrice: «Scrivo un fiore a un petalo | diserbo una poesia scritta tra veglia e sonno | sfrondo | strappo | ripianto nei miei sogni» (p. 48).

5 Un testo evocativo, dalla parola lirica e quasi «oracolare» (p. 10), forma poetica che mescola mirabilmente le lingue dell'autrice - francese, arabo, aramaico - ma che parla soprattutto la «lingua tintinnante come biglie di vetro nelle [...] tasche di bimbi» (p. 51). 